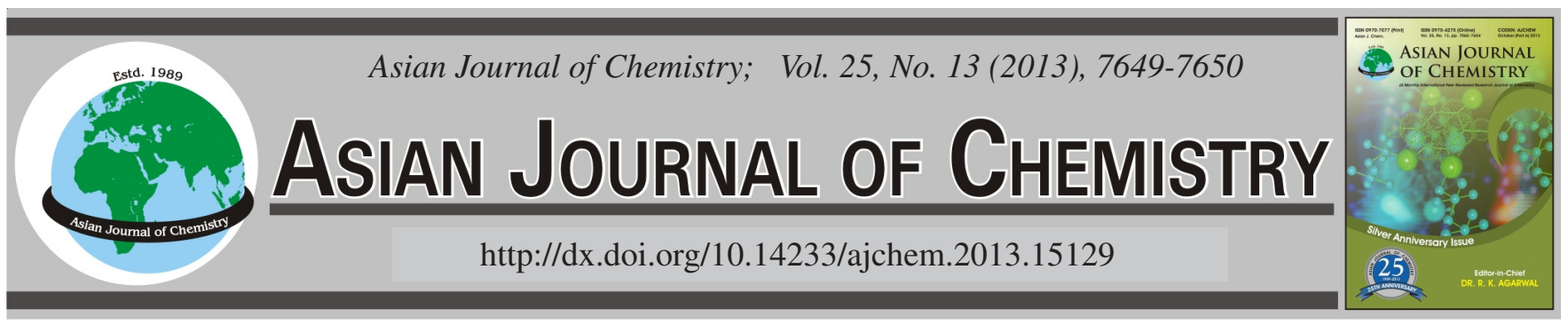

NOTE

\title{
A Mild, Aromatization of Cyclic Compounds and Oxidation of Amino Groups to Carbonyls using o-Iodoxybenzoic acid
}

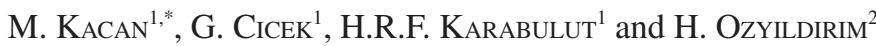

${ }^{1}$ Department of Chemistry, Faculty of Science, Trakya University, 22030 Edirne, Turkey

${ }^{2}$ Faculty of Education, Trakya University, 22030 Edirne, Turkey

*Corresponding author: Fax: +90 284 2351198; Tel: +90 532 7071514; E-mail: mesutkacan@ trakya.edu.tr

\begin{abstract}
A new, mild and efficient method has been developed for the synthesis of aromatic compounds and some carbonyls via the oxidative aromatization of amino cyclic compound by using hypervalent iodine reagent in DMSO at ambient temperature. The facile synthetic accessibility and it is as mild as non-hazardous nature render $o$-iodoxybenzoic acid equivalent of Dess-Martin periodinane reagent in organic oxidations.

Key Words: $o$-Iodoxybenzoic acid, Aromatization, Oxidation, N-Cyclohexylaniline.
\end{abstract}

The oxidizing reactants and methods are becoming important key reactions in the organic chemistry, especially hypervalent iodine compounds which are used as oxidizing reagents in many organic reactions. $o$-Iodoxybenzoic acid (IBX) is a readily available hypervalent iodine (V) compound first prepared in $1893^{1}$, but it was not used until the beginning of the last decade because of its solubility problem in common organic solvents. Frigerio and Santagostino ${ }^{2}$ showed for the first time in 1994 that $o$-iodoxybenzoic acid can be employed in DMSO for the conversion of alcohols to the carbonyl compounds. In the recent years, Nicolau and co-workers have uncovered a range of transformations mediated by IBX in DMSO elevated temperature ${ }^{3}$. In 2003, IBX was used as a mild, selective and high yielding method for oxidation of sulfides to sulfoxides in tetraethylammonium bromide (TEAB) as an IBX activator in a variety of solvents ${ }^{4}$. In the same year Nicolau and co-workers ${ }^{5}$ showed a different side of IBX. It is a powerful single-electron-transfer (SFT) agent that readily accepts new heteroatom-based ligands and thus can (1) effect the oxidation of ketones, aldehydes and sillyl enol ethers to the corresponding $\alpha, \beta$-unsaturated carbonyl compounds (2) oxidize benzyl positions and (3) facilitate the cyclization of $\mathrm{N}$-aryl amide, (thio) carbamates and ureas to afford various heterocyclic and amino sugars ${ }^{6}$.

Though IBX finds widespread use in oxidative transformations, there are a few reports on IBX-mediated oxidation of amines. Also there is no available report on IBX mediated oxidation of cyclic compounds converting to the aromatic compounds. First of all, here-in we report the successful direct oxidation of multifarious amines to the corresponding imines and furthermore amides by IBX under mild conditions in range of yields. Imines and carbonyls are ubiquitous and useful intermediates within the domain of synthesis, acting as electrophilic and nucleophilic participants at the reactions. We also report the amino substituted cyclic compound is converted to the corresponding amino aromatic compound via a fantastic mechanistic way. Aromatization of cyclic compounds is always significant in the organic synthesis and thus many methods have been developed.

All chemicals and the solvents were purchased from Aldrich Chemicals and used without further purification. NMR spectra were recorded on a Varian $300 \mathrm{MHz}$ for ${ }^{1} \mathrm{H}$ and $75 \mathrm{MHz}$ for ${ }^{13} \mathrm{C}$ in $\mathrm{CDCl}_{3}$ solution.

General procedure: In a flask $(250 \mathrm{~mL}), \operatorname{DMSO}(60 \mathrm{~mL})$ was added dropwise into IBX (24 mmol) for $15 \mathrm{~min}$ and then the solution was stirred for $0.5 \mathrm{~h}$ at room temperature. Then amino compound (diethylamine or cyclohexylamine) (22 $\mathrm{mmol}$ ) was poured into the mixture and the last mixture was heated to $45^{\circ} \mathrm{C}$ for $0.5 \mathrm{~h}$. The reaction was monitored with TLC. To the reaction, mixture $\mathrm{Na}_{2} \mathrm{~S}_{2} \mathrm{O}_{3}(30 \mathrm{~mL})$ and ethyl acetate $(30 \mathrm{~mL})$ were added and the mixture was cooled to $5{ }^{\circ} \mathrm{C}$ in $15 \mathrm{~min}$ and crystallized iodobenzoic acid was filtered out. The liquid phase was extracted with alkaline solution three times and washed with brine and dried with $\mathrm{Na}_{2} \mathrm{SO}_{4}$. It was 
filtrated and solvent was removed under reduced pressure to give crude products. Column chromatography methods were used to separate.

N-Cyclohexylaniline: ${ }^{1} \mathrm{H} \mathrm{NMR}\left(\mathrm{CDCl}_{3}\right) \delta 7.25-7.18(\mathrm{~m}$, $2 \mathrm{H}$, aromatic), 6.56-6.78 (m, $3 \mathrm{H}$, aromatic), $3.48(\mathrm{br}, 1 \mathrm{H}, \mathrm{NH})$, 3.29-3.38 (m, 1H, CH), 2.02-2.06 (m, 2H, $\left.\mathrm{CH}_{2}\right), 1.60-1.82$ $\left(\mathrm{m}, 3 \mathrm{H}, \mathrm{CH}_{2}\right), 1.42-1.06\left(\mathrm{~m}, 5 \mathrm{H}, \mathrm{CH}_{2}\right) .{ }^{13} \mathrm{C} \mathrm{NMR}\left(\mathrm{CDCl}_{3}\right) \delta$ 147.8, 129.9, 116.6, 113.8, 51.0, 33.9, 26.0, 25.8. DEPT: 129.9, 116.6, $113.8\left(\mathrm{CH}_{2}\right), 51.0,33.9,26.0,25.8(\mathrm{CH}), \mathrm{GC}-\mathrm{MS} ;(9,19$ $\mathrm{dk}-175 \mathrm{~m} / \mathrm{z})$.

In this context we were pleased to observe as we proceeded to investigate the potential of IBX in this transformation, that amine substrate could be smoothly and rapidly oxidized under mild conditions at different equivalences in a range of yield. In here, symmetrical secondary amine (diethylamine) was employed at the 1.1 equivalent of IBX in $0.2-0.5 \mathrm{mmol}$ scale in DMSO and the smooth reaction was observed and the expected product was obtained in excellent yield ${ }^{5}$ (Fig. 1).

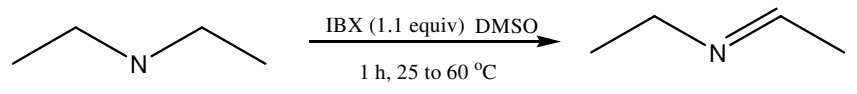

Fig. 1. Reaction of diethylamine with IBX (1.1 equiv.) in DMSO

The same reaction was also run with an excess amount of (1:4) IBX and product mixtures were obtained (Fig. 2).

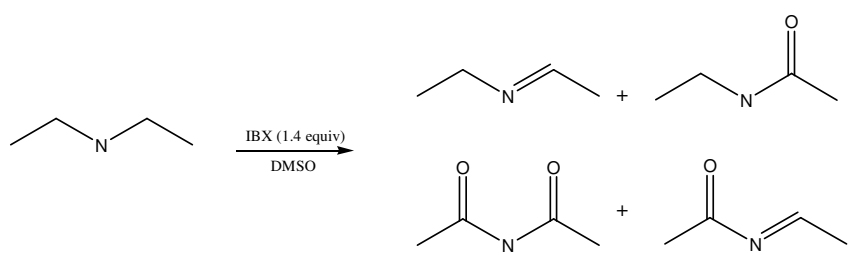

Fig. 2. Reaction of diethylamine with IBX (1.4 equiv.) in DMSO

As seen from the above reaction, if there is IBX in the reaction medium, oxidation would happen until the consumption of IBX. After this reaction we thought that we could convert the cyclic compound which is includes substituted amine group (cyclohexylamine) to the aromatic compound by using an excess amount of IBX (Fig. 3).

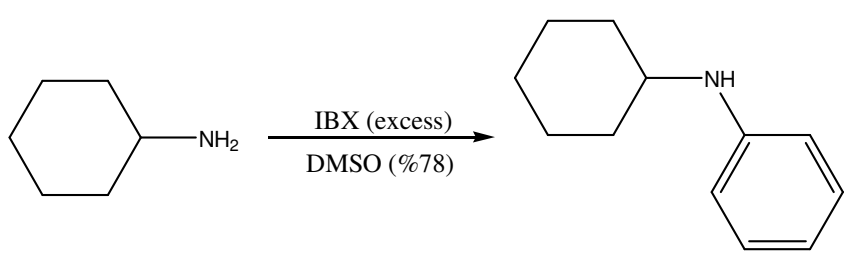

Fig. 3. Reaction of cyclohexylamine with excess IBX in DMSO

\section{Conclusion}

As expected, cyclohexylamine is reacted with the excess amount of $o$-iodoxybenzoic acid and $\mathrm{N}$-cyclohexyl aniline was obtained. We offered the proposed mechanism for this reaction as shown below (Fig. 4)

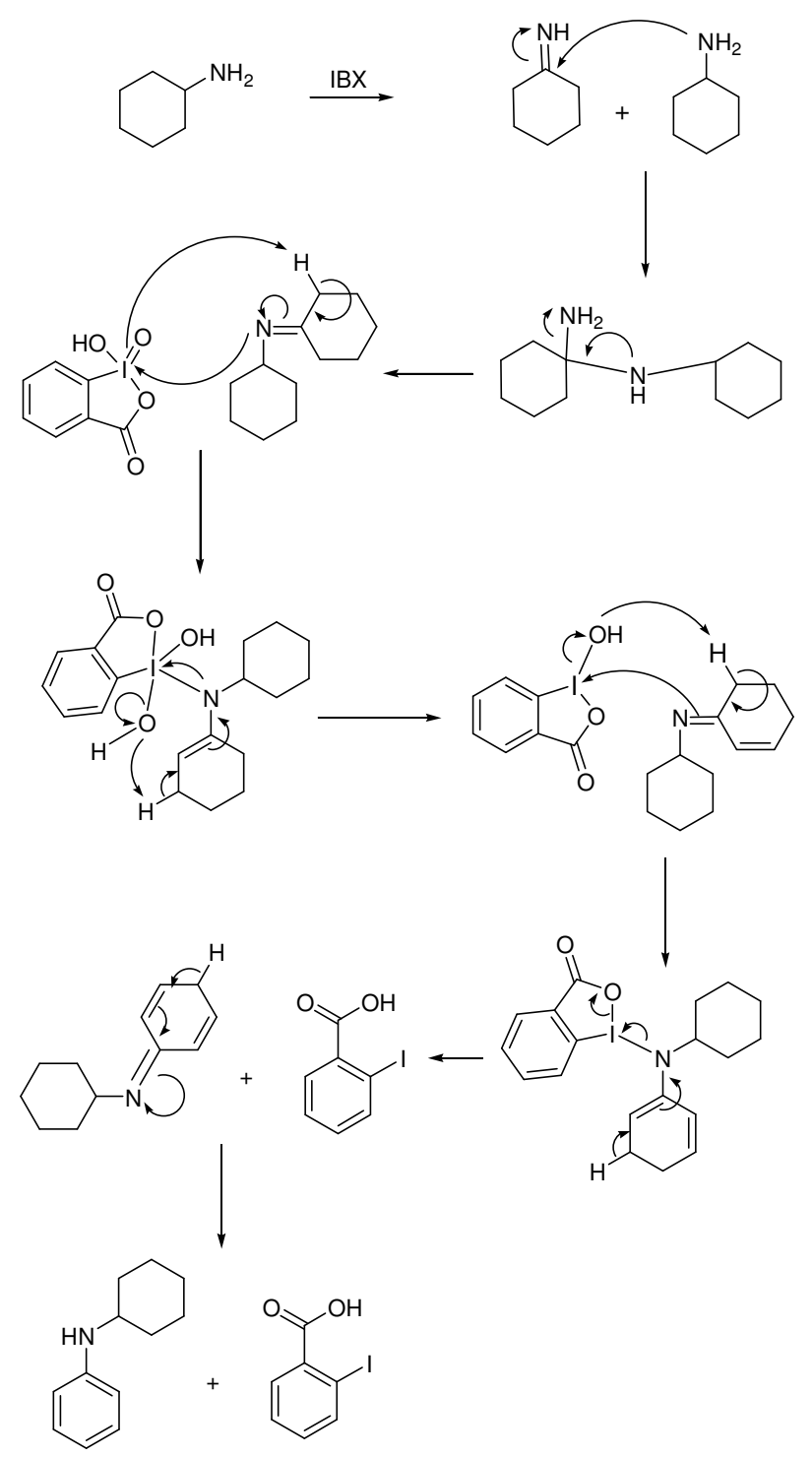

Fig. 4. Proposed mechanism

\section{REFERENCES}

1. C. Hartman and V. Meyer, Ber. Dtsch. Chem. Ges, 26, 1727 (1893).

2. (a) M. Frigerio and M. Santagostino, Tetrahedron Lett., 35, 8019 (1994); (b) M. Frigerio, M. Santagostino, S. Sputore and G. Palmisano, J. Org. Chem., 60, 7292 (1995).

3. (a) K.C. Nicalaou, P.S. Baran and Y.L. Zhang, J. Am. Chem. Soc., 123, 3183 (2001); (b) K.C. Nicalaou, K. Sujita, P.S. Baran and Y.L. Zhang, Angew. Chem. Int. Ed., 40, 207 (2001); (c) K.C. Nicalaou, P.S. Baran, Y.L. Zhang and K. Sujita, Angew. Chem. Int. Ed., 40, 2145 (2001).

4. V.G. Shulka, P.D. Salgaonkar and K.G. Akamanchi, J. Org. Chem., 68, 5422 (2003).

5. K.C. Nicalaou, J.N. Mathison Casey and T. Montagnon, Angew. Chem. Int. Ed., 42, 4077 (2003).

6. (a) K.C. Nicalaou, T. Montagnon, P.S. Baran and Y.L. Zhang, J. Am. Chem. Soc., 124, 2245 (2002); (b) K.C. Nicalaou, T. Montagnon and P.S. Baran, Angew. Chem. Int. Ed., 114, 1035 (2002); (c) K.C. Nicalaou, Y.L. Zhang and P.S. Baran, Angew. Chem. Int. Ed., 112, 636 (2000); (e) K.C. Nicalaou, P.S. Baran, Y.L. Zhang and S. Barluenga, J. Am. Chem. Soc., 124, 2233 (2002). 